\title{
Erratum to: Sexual Dimorphism and Estrogen Action in Mouse Liver
}

Sara Della Torre, Federica Lolli, Paolo Ciana, and Adriana Maggi

\section{Erratum to:}

Chapter 8 in: F. Mauvais-Jarvis (ed.), Sex and Gender Factors Affecting Metabolic Homeostasis, Diabetes and Obesity, Advances in Experimental Medicine and Biology 1043, https://doi.org/10.1007/978-3-319-70178-3_8

The family name of corresponding author of this chapter Sara Della Torre was published as Torre in the book published initially. Now it has been corrected as Della Torre as per author's request.

The updated online version of this chapter can be found at https://doi.org/10.1007/978-3-319-70178-3_8 